\title{
Endothelin-1 Inhibits Background Two-Pore Domain Channel TASK-1 in Primary Human Pulmonary Artery Smooth Muscle Cells
}

\author{
Bi Tang1, Yingji Li ${ }^{1}$, Chandran Nagaraj ${ }^{2}$, Rory E. Morty ${ }^{3}$, Sabine Gabor ${ }^{4}$, Elvira Stacher ${ }^{5}$, Robert Voswinckel ${ }^{3}$, \\ Norbert Weissmann ${ }^{3}$, Katharina Leithner ${ }^{1}$, Horst Olschewski ${ }^{1}$, and Andrea Olschewski ${ }^{2}$ \\ ${ }^{1}$ Department of Pulmonology, University Clinic of Internal Medicine, and ${ }^{2}$ Experimental Anesthesiology, University Clinic of Anesthesia and \\ Intensive Care Medicine, ${ }^{4}$ Department of Thoracic and Hyperbaric Surgery, University Clinic of Surgery, and ${ }^{5}$ Institute of Pathology, Medical \\ University of Graz, Graz, Austria; and ${ }^{3}$ Department of Internal Medicine II, University Clinic Giessen, Giessen, Germany
}

\begin{abstract}
Endothelin (ET)-1 causes long-lasting vasoconstriction and vascular remodeling by interacting with specific G-protein-coupled receptors in pulmonary artery smooth muscle cells (PASMCs), and thus plays an important role in the pathophysiology of pulmonary arterial hypertension. The two-pore domain $\mathrm{K}^{+}$channel, TASK-1, controls the resting membrane potential in human PASMCs (hPASMCs), and renders these cells sensitive to a variety of vasoactive factors, as previously shown. ET-1 may exert its vasoconstrictive effects in part by targeting TASK-1. To clarify this, we analyzed the ET-1 signaling pathway related to TASK-1 in primary hPASMCs. We employed the whole-cell patch-clamp technique combined with TASK-1 small interfering RNA (siRNA) in hPASMC and the isolated, perfused, and ventilated mouse lung model. We found that ET-1 depolarized primary hPASMCs by phosphorylating TASK-1 at clinically relevant concentrations. The ET sensitivity of TASK-1 required $\mathrm{ET}_{\mathrm{A}}$ receptors, phospholipase $C$, phosphatidylinositol 4,5-biphosphate, diacylglycerol, and protein kinase $C$ in primary hPASMCs. The ET-1 effect on membrane potential and TASK-1 was abrogated using TASK-1 siRNA. This is the first time that the background $\mathrm{K}^{+}$channel, TASK1 , has been identified in the ET-1-mediated depolarization in native hPASMC, and might represent a novel pathologic mechanism related to pulmonary arterial hypertension.
\end{abstract}

Keywords: endothelin-1; TASK-1 channel; membrane potential; pulmonary hypertension

Endothelin (ET)-1 is considered to be a major player within the pathologic mechanisms involved in pulmonary arterial hypertension $(\mathrm{PAH})(1,2)$, and specific antagonists of ET-1 receptors represent an important pillar of modern therapy of this devastating disease $(3,4)$. In pulmonary artery smooth muscle cells (PASMCs), ET-1 causes long-lasting vasoconstriction (5) and excessive proliferation (6-8), contributing to vascular remodeling. $\mathrm{K}^{+}$channels determine the membrane potential of PASMCs, and represent an important controller of their calcium homeostasis $(9,10)$. Furthermore, it is now well established that inhibition of $\mathrm{K}^{+}$channels (for example, by serotonin or hypoxia) causes membrane depolarization and stimulates PASMC proliferation (11-13). In our previous study, we described the voltage-independent background two-pore domain $\mathrm{K}^{+}$channel,

(Received in original form October 26, 2008 and in final form January 6, 2009) Correspondence and requests for reprints should be addressed to Andrea Olschewski, M.D., Ph.D., Experimental Anesthesiology of the University Clinic of Anesthesia and Intensive Care Medicine, Medical University of Graz, Auenbruggerplatz 29, A-8036 Graz, Austria. E-mail: andrea.olschewski@medunigraz.at

This article has an online supplement, which is accessible from this issue's table of contents at www.atsjournals.org

Am J Respir Cell Mol Biol Vol 41. pp 476-483, 2009

Originally Published in Press as DOI: 10.1165/rcmb.2008-0412OC on February 2, 2009

Internet address: www.atsjournals.org

\section{CLINICAL RELEVANCE}

Endothelin-1 causes long-lasting vasoconstriction and vascular remodeling by interacting with specific G-proteincoupled receptors in human pulmonary artery smooth muscle cells. The inhibition of the background $\mathrm{K}^{+}$channel TASK-1 by endothelin-1 might represent a novel pathologic mechanism related to pulmonary arterial hypertension.

TWIK-related acid-sensitive $\mathrm{K}^{+}$channel (TASK)-1, in human PASMCs (hPASMCs) (14). Several lines of evidence indicate that TASK-1 plays an important role in the human pulmonary circulation. First, the TASK-1 channel contributes substantially to the $\mathrm{K}^{+}$conductance, and sets resting membrane potential in hPASMCs (14), where other $\mathrm{K}^{+}$channels, such as voltage-gated $\left(\mathrm{K}_{\mathrm{v}}\right)$ or calcium-dependent $\mathrm{K}^{+}$channels are not activated. Moreover, TASK-1 is modulated by $\mathrm{pH}$, protein kinases, hypoxia, or vasoactive factors, such as prostacyclin (14-16). Finally, two-pore domain channels are supposed to be involved in hypoxic pulmonary vasoconstriction (17).

Based on their properties, both TASK-1 channels and ET-1 might interact in the pathogenesis of PAH. Although numerous studies have investigated ion channels in PAH, the TASK-1 in hPASMC has not been taken into account. Considering the features of TASK-1, we hypothesized that ET-1 might inhibit TASK-1 channels. In particular, to date, the molecular transduction mechanism for inhibition of TASK-1 in native human cells is poorly understood. In the present study, we investigated the signaling pathway and effects of ET-1 on TASK-1 in primary hPASMCs, and found the pathway from $\mathrm{ET}_{\mathrm{A}}$ receptors, through phospholipase C (PLC), phosphatidylinositol 4,5-biphosphate $\left(\mathrm{PIP}_{2}\right)$, diacylglycerol (DAG), and protein kinase $(\mathrm{PK}) \mathrm{C}$ to TASK-1.

\section{MATERIALS AND METHODS}

\section{Preparation of Human Primary PASMCs}

Primary SMC were isolated from human pulmonary arteries from patients $(n=19)$ undergoing lung surgery for lung cancer without a history of pulmonary vascular disease or arterial hypoxemia, as described previously (14). The study protocol for tissue donation was approved by the Institutional Review Board of the Medical University of Graz in accordance with national law, and with guidelines on Good Clinical Practice/International Conference on Harmonization. Written, informed consent was obtained from each individual patient.

The adventitia from small arteries with diameters of less than $1 \mathrm{~mm}$ was carefully removed under microscopic guidance, and media pieces less than $1 \mathrm{~mm}^{3}$ were placed onto 16 -mm coverslips with $500 \mu$ l culture medium (Lonza SMC Medium; Lonza Group Ltd, Basel, Switzerland). Cells were maintained at $37^{\circ} \mathrm{C}$, medium was initially changed after 
24 hours, and then every 48 hours thereafter. SMC identity was verified by characteristic appearance in phase-contrast microscopy, The purity of PASMC cultures was confirmed by indirect immunofluorescent antibody staining for smooth muscle-specific isoforms of $\alpha$-actin and myosin (at least $95 \%$ of cells stained positive), and lack of staining for von Willebrand factor.

\section{Electrophysiology}

The whole-cell patch-clamp technique on hPASMC was used as previously described to measure the resting membrane potential under current clamp, and macroscopic TASK-1 $\mathrm{K}^{+}$current under voltage clamp $(14,18)$. Cells were superfused at room temperature with bath solution of the following composition: $140.5 \mathrm{mM} \mathrm{NaCl}, 5.5 \mathrm{mM} \mathrm{KCl}$, $1.5 \mathrm{mM} \mathrm{CaCl}, 1 \mathrm{mM} \mathrm{MgCl}, 10 \mathrm{mM}$ glucose, $0.5 \mathrm{mM} \mathrm{Na}_{2} \mathrm{HPO}_{4}$, $0.5 \mathrm{mM} \mathrm{KH}_{2} \mathrm{PO}_{4}, 10 \mathrm{mM}$ HEPES ; adjusted to $\mathrm{pH} 7.3$ with $\mathrm{NaOH}$. Pipettes were filled with the following solutions: $20 \mathrm{mM} \mathrm{KCl}, 135 \mathrm{mM}$ $\mathrm{K}$-methanesulphonate (to suppress $\mathrm{Cl}^{-}$currents), $1 \mathrm{mM} \mathrm{MgCl}_{2}$, $0.5 \mathrm{mM} \mathrm{CaCl}_{2}, 2 \mathrm{mM}$ Na2ATP, $3 \mathrm{mM}$ EGTA, $20 \mathrm{mM}$ HEPES; $\mathrm{pH}$ adjusted to 7.2 with $\mathrm{KOH}$. The free $\left[\mathrm{Ca}^{2+}\right]$, calculated using Maxchelator (http://www.stanford.edu/\%7Ecpatton/maxc.html), was $30 \mathrm{nM}$. To isolate the non-inactivating TASK-1 $\mathrm{K}^{+}$current $\left(\mathrm{I}_{\mathrm{KN}}\right)$ from other voltage-dependent $\mathrm{K}^{+}$currents, cells were clamped at $0 \mathrm{mV}$ for at least 5 minutes, as previously described $(14,18)$. As we have previously shown, under these conditions, tetraethylammonium-chloride (TEA), Iberiotoxin (ITX), or 4-aminopyridine had no significant effect on $I_{\mathrm{KN}}$ (14). Pipettes pulled from borosilicate glass tube (GC 150; Clark Electromedical Instruments, Pangbourne, UK) were fabricated on a model P-97 electrode puller (Sutter Instruments, Novato, CA) and fire polished to give a final resistance of 2-3 $\mathrm{M} \Omega$ for whole-cell recording. The patch-clamp amplifier was an Axopatch 200 B (Axon Instruments, Foster City, CA), and the digital-analog converter was a DigiData 1,320 (Axon Instruments) in all voltage- and current-clamp experiments. Offset potentials were nulled directly before formation of a seal. No leak subtraction was made. Cells expressing holding current at $-70 \mathrm{mV}$ of $10 \mathrm{pA}$ before or during the recordings were discarded. Estimation of cell capacitance (in $\mathrm{pF}$ ) was made from whole-cell capacitance compensation. For resting membrane potential (Em), cells were held in current-clamp at their resting Em (without current injection). The effective corner frequency of the low-pass filter was $0.5-5.0 \mathrm{kHz}$. The frequency of digitization was at least twice that of the filter. The data were stored and analyzed with commercially available pCLAMP 9.0 software (Axon Instruments).

\section{Solutions and Chemicals}

All compounds were purchased from Sigma Chemical Co. (St. Louis, $\mathrm{MO})$. All drugs were dissolved in experimental solution, with the exception of anandamide, which was dissolved in $50 \%$ (vol $/ \mathrm{vol}$ ) ethanol in water. At this concentration, the vehicle alone had no effect on $\mathrm{K}^{+}$ current or resting membrane potential. The $\mathrm{pH}$ of solutions containing drugs was tested and corrected to eliminate potential $\mathrm{pH}$-induced effects.

\section{Design and Transfection of Small Interfering RNA for Human TASK-1}

Transfection of TASK-1 small interfering RNA (siRNA) was performed exactly as described previously (14). The RNA extraction and electrophysiological measurements were performed 48-72 hours after transfection of siRNAs. For assessment of transfection efficiency, we used an FITC-conjugated siRNA (Qiagen, Hilden, Germany), the intracellular location of which was assessed by direct visualization of the FITC by fluorescence microscopy after transfection.

\section{Relative mRNA Quantification}

Real-time PCR was used for relative quantification of the TASK-1 and PKCA mRNA, as described previously (14). Both GAPD and HMBS were used as reference genes (see Table E1 in the online supplement). The primers were designed to be intron spanning where possible, and maximal specific for the target genes. The reactions were performed in an ABI 7,700 Sequence Detection System (Applied Biosystems, Foster City, CA) with SYBR green I as fluorogenic probe in $25-\mu$ l reactions containing $2 \mu \mathrm{l}$ cDNA sample, $1 \times$ qPCR Mastermix for SYBR green I
(Eurogentec, Seraing, Belgium), and 45 pmol forward and reverse primer (Table E1). The cycling protocol was one cycle of $50^{\circ} \mathrm{C}$ for 2 minutes, one cycle of $95^{\circ} \mathrm{C}$ for 6 minutes, and 45 cycles of $95^{\circ} \mathrm{C}$ for 5 seconds, $60^{\circ} \mathrm{C}$ for 5 seconds, and $73^{\circ} \mathrm{C}$ for 10 seconds. The data for the amplification curves were acquired after the extension phase at $73^{\circ} \mathrm{C}$. After amplification, a melting curve was recorded and analyzed to identify possible contributions of unspecific products to the fluorescence signal. Additionally, an agarose gel analysis was performed to confirm the primary formation of a single specific PCR product.

The background signal of the amplification curves was corrected for each gene individually with the signals recorded from cycle 3 to cycles 15-25, dependent on the onset of the exponential signal increase. The threshold value was set for each gene in the middle of the overlapping region of the exponential phases. Each gene was measured in duplicate in two independent experiments. The $\Delta \mathrm{ct}$ values for each target gene were calculated for both reference genes using the averaged ct values by the formula, $\Delta \mathrm{ct}=\mathrm{ct}_{\text {reference }}-\mathrm{ct}_{\text {target }}$. The $\Delta \mathrm{ct}$ of both reference genes were averaged and used to calculate the $\Delta \Delta \mathrm{ct}$ value by the formula, $\Delta \Delta \mathrm{ct}=\Delta \mathrm{ct}_{\text {siRNA }}-\Delta \mathrm{ct}_{\text {control}}$. According to an amplification efficiency of approximately 2 , the factors of differential target expression can be calculated by $\mathrm{f}=2^{\Delta \Delta \mathrm{ct}}$ (the efficiencies for the amplification of the target genes have been determined in pilot experiments, and were all greater than 1.98 or $98 \%$, respectively; data not shown). The error of the $\Delta \Delta$ ct values was estimated from the average SD of replicates using the error propagation by Gauss.

\section{Immunoprecipitation}

Primary SMCs were solubilized as described previously (19) in an extraction buffer supplemented with $1 \mathrm{mM}$ sodium orthovanadate, $10 \mathrm{mM}$ sodium pyrophosphate, $5 \mathrm{mM} \beta$-glycerophosphate, and $50 \mathrm{mM}$ sodium fluoride. The TASK-1 was immunoprecipitated from cell lysates ( 4 hours, $4^{\circ} \mathrm{C}$ ) with rabbit anti-TASK-1 (Alomone, Jerusalem, Israel) (20). Antibodies were chemically coupled to protein A-sepharose beads with a Seize Immunoprecipitation Kit (Pierce, Rockford, IL). Immunoprecipitates were washed to a final stringency of $470 \mathrm{mM} \mathrm{NaCl}$ in extraction buffer. Immunoprecipitates were resolved on a $10 \%$ Tris-glycine SDS-PAGE gel, and blots were probed with rabbit anti-TASK-1 (1:500; Alomone), mouse antiphosphotyrosine (Cell Signaling Technologies, Beverly, MA; 1:1750), or mouse anti-phospho(Ser/Thr) (1:1,000; Cell Signaling Technologies) antibodies.

\section{Isolated, Perfused, and Ventilated Mouse Lungs}

All organ experiments were approved by the local authorities (Regierungspräsidium Giessen). Lungs from C57BL/6 mice (Charles River Laboratories, Sulzfeld, Germany) were removed from the chest in deep anesthesia, artificially ventilated, and perfused blood free, as described previously (21) (for more details, see the online supplement). After an initial steady-state period of 30 minutes, ET-1 was added in to the buffer in increasing doses every 25 minutes. In experiments with anandamide, this agent was applied to the buffer 20 minutes before the first ET-1 admixture. Delta pulmonary arterial pressure (Ppa) indicates the Ppa after application of ET-1 at a chosen concentration minus the Ppa before.

\section{Statistical Analysis}

Numerical values are given as means $( \pm \mathrm{SE})$ of $n$ cells. Intergroup differences were assessed by a factorial ANOVA with post hoc analysis with Fisher's least significant difference test, or Student's unpaired and paired $t$ tests, as appropriate. $P$ values less than 0.05 were considered significant.

To determine the blocking potency of ET-1 on TASK-1, concentration-inhibition curves were constructed from the current inhibition by the drug at $0 \mathrm{mV}$. I/I $\mathrm{I}_{0}$ is the current in the presence of ET-1 as a fraction of the current before ET-1 application. The normalized amplitudes of currents were fitted by means of a nonlinear least-squares method with the equation: $1\left[1+(\mathrm{c} / \mathrm{IC} 50)^{\mathrm{h}}\right]^{-1}$, where $c$ is the drug concentration, $\mathrm{IC}_{50}$ is the concentration giving a half-maximum effect, and $\mathrm{h}$ is the Hill coefficient. Because the Hill coefficient was less than 1 ( 0.9 in all curves), it was set to 1 , accounting for a 1:1 binding stoichiometry. 
A
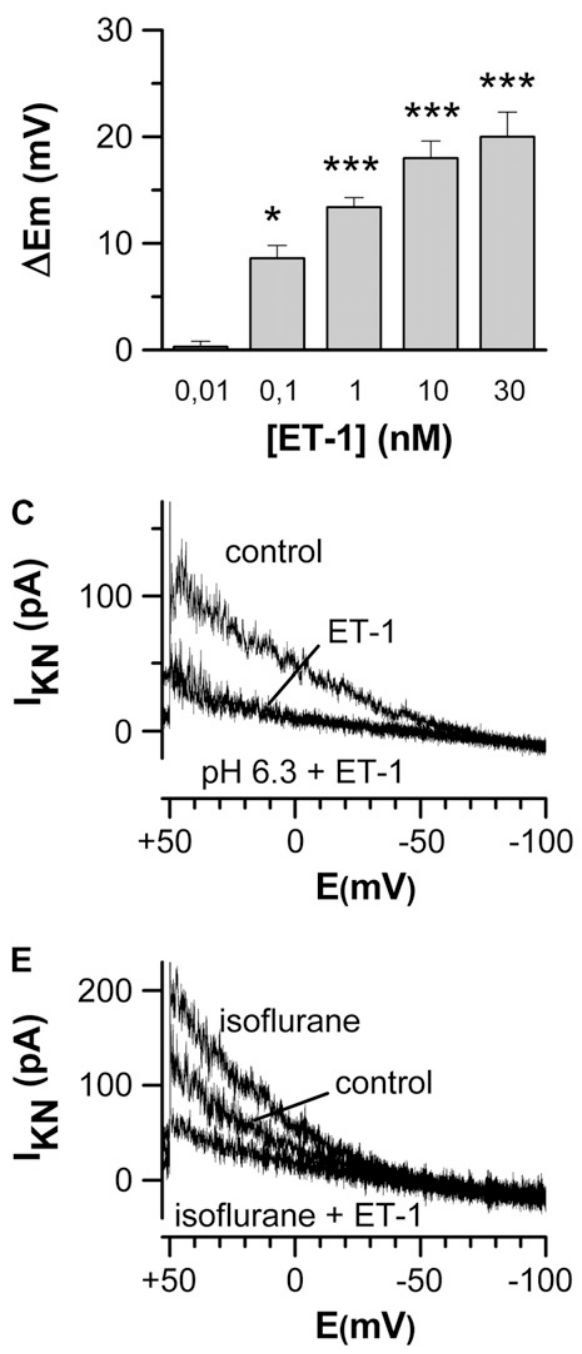

B
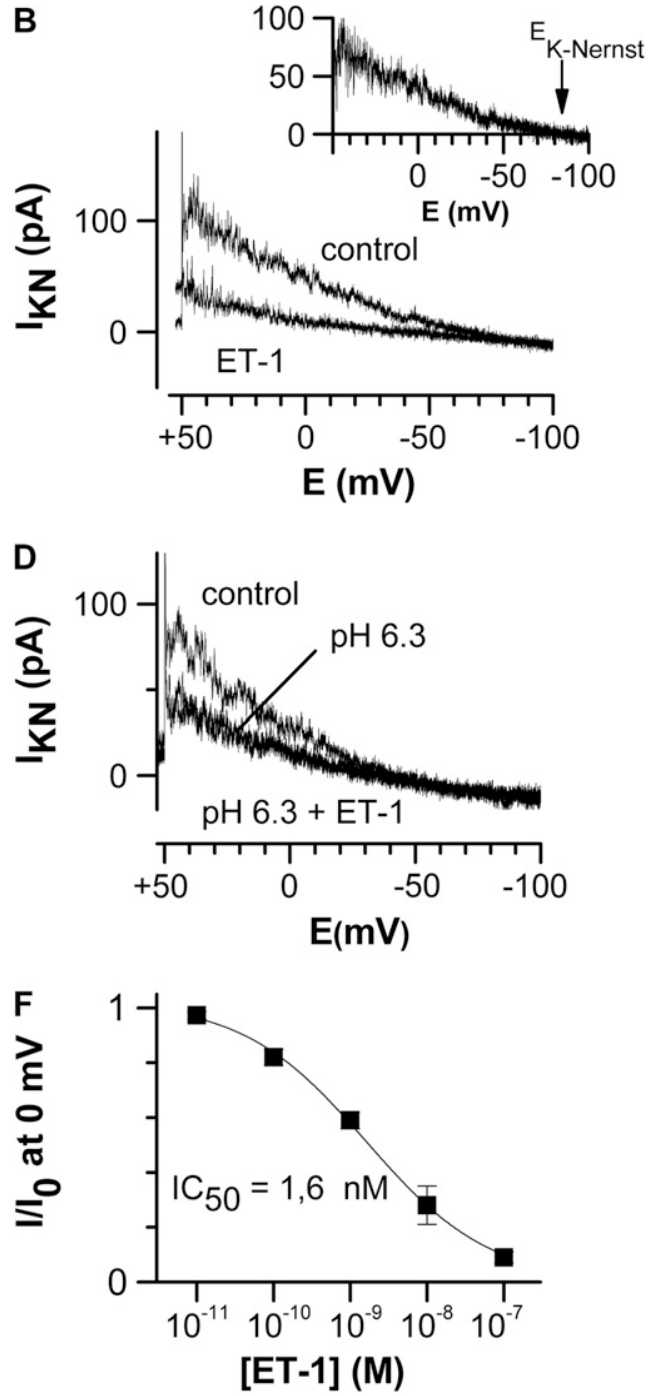

Figure 1. Endothelin (ET)-1 blocks noninactivating TASK-1 $\mathrm{K}^{+}$current $\left(\mathrm{I}_{\mathrm{KN}}\right)$ in primary human pulmonary artery smooth muscle cell (hPASMC) at clinically relevant concentrations. (A) ET-1 significantly depolarized primary hPASMCs $(n=5$ each group; $\left.{ }^{*} p<0.05,{ }^{* * *} p<0.001\right)$. (B) Effect of $10 \mathrm{nM}$ ET-1 on $I_{\mathrm{KN}}$ recorded during ramp, voltage protocol (inset, left), and "difference" currents trace, obtained by subtracting current amplitudes in the presence of ET-1 from those obtained under control conditions (right). E, voltage. Difference current reversed close to $-84 \mathrm{mV}$, as expected for a $\mathrm{K}^{+}$-selective conductance under these conditions. (C) Representative recordings for $I_{K N}$ after applying ET-1 (10 nM) and when ET-1 was applied at $\mathrm{pH}$ 6.3. (D) $\mathrm{I}_{\mathrm{KN}}$ recorded in control, following acidification to $\mathrm{pH} 6.3$ and after application of ET-1 (10 nM) under acidification. (E) ET-1 reverses $\mathrm{I}_{\mathrm{KN}}$ opening by isoflurane $(1 \mathrm{mM}) .(F)$ Concentration-response curve for ET-1. $\mathrm{I} / \mathrm{I}_{0}$ is the current in the presence of ET-1 expressed as a fraction of the current before ET-1 application. The line is the best fit to the Hill equation using an $\mathrm{IC}_{50}$ of $1.6( \pm 0.3) \mathrm{nM}$.

\section{RESULTS}

\section{Modulation of TASK-1 by ET-1 at Clinically Relevant Concentrations in Primary hPASMCs}

ET-1 significantly and dose dependently depolarized hPASMCs, as shown in Figure 1A. Application of ET-1 markedly reduced the non-inactivating $\mathrm{K}^{+}$current $\left(\mathrm{I}_{\mathrm{KN}}\right)$ in primary hPASMCs in the presence of the voltage-activated $\mathrm{K}^{+}$ channel inhibitor, 4-aminopyridine $(5 \mathrm{mM})$ (data not shown). Figure $1 \mathrm{~B}$ shows the effect of ET-1 in representative recordings from the holding potential of $0 \mathrm{mV}$, after the cells were clamped at $0 \mathrm{mV}$ for least 5 minutes to inactivate voltage-dependent $\mathrm{K}^{+}$ channels $(14,18)$. The voltage was stepped to $60 \mathrm{mV}$, and then ramped to $-100 \mathrm{mV}$ over a period of 1.6 seconds. The ET-1sensitive current, obtained by subtracting the current remaining in the presence of ET-1 from that obtained under control conditions (Figure 1B, inset), was reversed close to $-84 \mathrm{mV}$, the calculated Nernst equilibrium potential for $\mathrm{K}^{+}$under these conditions. The effect of ET-1 on $\mathrm{I}_{\mathrm{KN}}$ was completely abolished by preapplication of $10 \mu \mathrm{M}$ anandamide (see the online supplement), a blocker of TASK channels $(18,22)$. Because TASK-2 and TASK-3 are not expressed in hPASMC (14), this finding suggests that ET-1 acts on TASK-1 current. Another marker of TASK channels is their sensitivity to extracellular $\mathrm{pH}$ and to volatile anesthetics. As illustrated in Figure 1C, the ET-1inhibited current was not further affected by acidosis ( $\mathrm{pH} \mathrm{6.3).}$
Consistently, reducing the $\mathrm{pH}$ from 7.3 to 6.3 suppressed the $\mathrm{I}_{\mathrm{KN}}$ and, under acidification, ET-1 did not further inhibit the current (Figure 1D). Application of isoflurane (1 $\mathrm{mM})$ enhanced $\mathrm{I}_{\mathrm{KN}}$ (Figure 1E). Consistent with the involvement of TASK-1 channels in this facilitation, it was blocked by ET-1. The concentration-response curve for the inhibition of TASK-1 by ET- 1 measured and calculated at $0 \mathrm{mV}$ gave an $\mathrm{IC}_{50}$ of 1.6 $( \pm 0.3) \mathrm{nM}$ (Figure $1 \mathrm{~F} ; n=5$ for each group).

To further confirm the role of TASK-1 in ET-1 pathway in hPASMC, we knocked down TASK-1 expression using TASK-1 siRNA (14). In the siRNA-transfected cells, no inhibition of the remaining current by ET-1 was detected compared with primary control hPASMC (Figure 2A) or to scrambled siRNA-transfected hPASMCs (data not shown). The histograms in Figure 2B summarize the effect of ET- 1 on $\mathrm{I}_{\mathrm{KN}}$ calculated at $0 \mathrm{mV}$, showing that there was no significant inhibition by ET-1 on the remaining current after the siRNA treatment. In addition, the siRNA-transfected cells showed a significantly less negative membrane potential $(-31 \pm 1 \mathrm{mV} ; P<0.001 ; n=6)$ compared with control cells $(-51 \pm 1 \mathrm{mV} ; n=45)$. It is noteworthy that, in the siRNA-transfected cells, ET-1 did not further change the membrane potential (from $-31 \pm 1$ to $-29 \pm 1 \mathrm{mV} ; P>0.05$; $n=6$ ), suggesting the crucial role of TASK-1 in the ET-1 pathway.

To investigate the possible physiologic relevance of TASK-1 for the ET-1-induced pulmonary vasoconstriction, we analyzed 

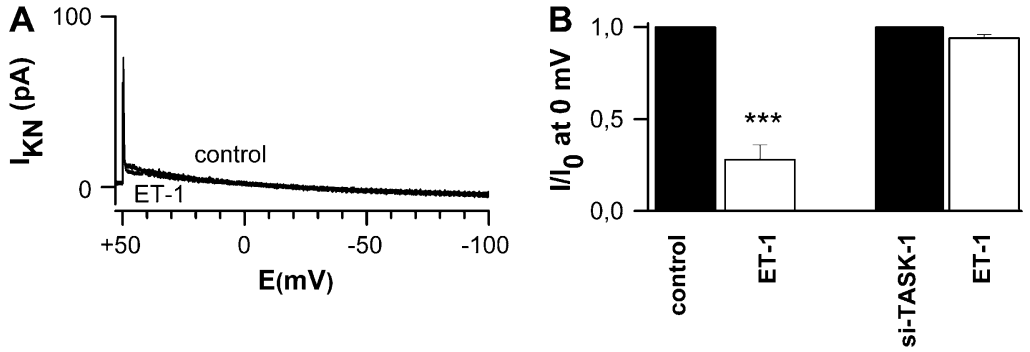

Figure 2. Lack of the ET-1 effect on $I_{\mathrm{KN}}$ in TASK-1-small interfering RNA (siRNA)-transfected hPASMCs $(A)$ Lack of ET-1 (10 nM) effect on $I_{K N}$ in TASK-1-siRNA-transfected hPASMC. (B) Histogram summarizes the effect of ET-1 on $\mathrm{I}_{\mathrm{KN}}$ calculated at $0 \mathrm{mV}$ in primary control and siRNA-transfected hPASMCs $\left(n=6\right.$ each group; $\left.{ }^{* * *} P<0.001\right)$. the ET-1-induced pressor response in the isolated, perfused mouse lungs. ET-1 induced a dose-dependent increase in Ppa (Figure E2). The pulmonary artery vasoconstriction was more pronounced when anandamide was given before the ET-1. The application of $8 \mathrm{nM}$ ET-1 increased Ppa with $15.6( \pm 2.3) \mathrm{mm}$ $\mathrm{Hg}$; when anandamide was given before ET-1, the increase was $23.8( \pm 1.0) \mathrm{mm} \mathrm{Hg}(P<0.01 ; n=5)$.

\section{Signaling Pathway of ET-1 in Primary hPASMCs}

ET-1 in humans binds to two types of receptors: $\mathrm{ET}_{\mathrm{A}}$ and $\mathrm{ET}_{\mathrm{B}}$. Both $\mathrm{G}$ protein-coupled receptors were detected in PASMCs. To investigate which receptor is involved in the inhibition of TASK-1 by ET-1, we used different ET-1 receptor antagonists: BQ123 $\left(\mathrm{ET}_{\mathrm{A}}\right.$ blocker; $\left.1 \mu \mathrm{M}\right)$; BQ788 $\left(\mathrm{ET}_{\mathrm{B}}\right.$ blocker; $\left.1 \mu \mathrm{M}\right)$; and

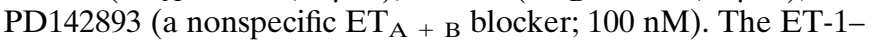
induced TASK-1 inhibition was completely abolished by preapplication of BQ123 and PD142893 (Figures 3A and 3C). In contrast, preapplication of BQ788 had negligible effect on the ET-1-induced inhibition of TASK-1 (Figures 3B and 3C), suggesting that the $\mathrm{ET}_{\mathrm{A}}$ receptor mediates the TASK-1 response to ET-1.

Next, we investigated the possible involvement of caveolae and phosphorylation of TASK-1 in the ET-1-mediated signal transduction in hPASMCs. To test these possibilities, PASMC were first analyzed for TASK-1 and caveolins via Western blot analysis. In hPASMC, we detected caveolin-1, -2 , and -3 , but the coimmunoprecipitation studies did not indicate any interaction among TASK-1 and these caveolins after stimulation with ET-1 (Figure E3).

To further assess the mechanism involved in ET-1-induced TASK-1 inhibition, hPASMCs were incubated for 10 minutes with ET-1 (10 nM). No differences in the tyrosine phosphorylation of TASK-1 was observed when ET-treated and untreated groups were compared ( $n=3$; Figure 4$)$. In contrast, the incubation with ET-1 stimulated the threonine phosphorylation of TASK-1, as was evident in TASK-1 immunoprecipitates probed with an anti-phosphothreonine antibody (Figure 4). Protein loading equivalence was demonstrated by probing immunoprecipitates with an anti-TASK-1 antibody (Figure 4). In patch-clamp studies, various $\mathrm{PKC}$ inhibitors, including Ro318220 (1 $\mu \mathrm{M})$, Gö6983 (10 $\mathrm{nM})$, and rottlerin (10 $\mathrm{nM})$ were used on the non-inactivating current response to ET-1 to confirm the PKC action. The pretreatment of the cells with the broadspectrum PKC blocker, Ro318220, and the classic, fast-acting PKC inhibitor, Gö6983, abolished the effect of ET-1 on TASK-1 current (Figure 5). Rottlerin (selective PKC- $\delta$ inhibitor) partially blocked the inhibition of TASK-1 by ET-1. Consistent with the effects of PKC inhibitors, preincubation with the PKA inhibitor, KT5720, did not lead to any change in ET-1-dependent TASK-1 inhibition (data not shown). Collectively, these results suggest that, in hPASMC, TASK-1 channels are inhibited by ET-1, primarily through $\mathrm{PKC}$-dependent pathways.

PKC may be activated in response to DAG and inositol 1,4,5-triphosphate $\left(\mathrm{IP}_{3}\right)$-stimulated increases in cytosolic calcium generated via PLC. To address the ET-1 signaling pathway downstream of the $\mathrm{G}$ protein-coupled receptor, $\mathrm{ET}_{\mathrm{A}}$, we combined pharmacological approaches with patch-clamp studies. First, we investigated the involvement of PLC-dependent signaling pathway(s) with the PLC antagonist, U-73122, on the ET-1-induced inhibition of TASK-1. Preapplication of U-73122 in hPASMCs completely abolished the effect of ET-1 $(10 \mathrm{nM})$ on $\mathrm{I}_{\mathrm{KN}}$ (Figure 6A). $\mathrm{PIP}_{2}$ serves as a substrate for
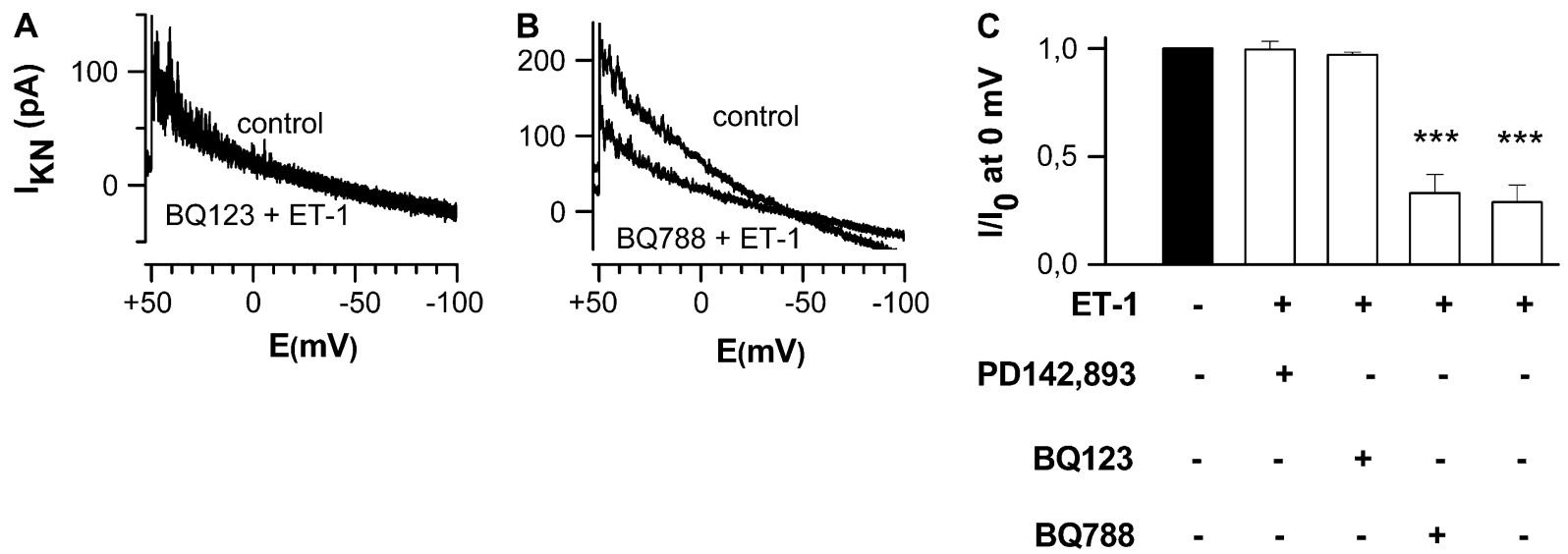

Figure 3. Blockade of $\mathrm{ET}_{\mathrm{A}}$ receptor abolishes the ET-1 effect on TASK-1 current in hPASMC. ( $A$ and $B$ ) Noninactivating current responses of TASK-1


were pretreated for 1 hour with the inhibitors before addition of ET-1 (10 nM). (C) Histogram summarizing the effect of ET-1 on TASK-1 current after pretreatment of hPASMCs with PD142893 (ET $\mathrm{A}_{+\mathrm{B}}$ antagonist; $\left.100 \mathrm{nM}\right), \mathrm{BQ} 123$, or BQ788 $(1 \mu \mathrm{M})(n=6$ for each group; $* * * P<0.001$ difference from ET-1-untreated cells). $\mathrm{l} / \mathrm{I}_{0}$ is the current in the presence of ET-1 expressed as a fraction of the current before ET-1 application. 

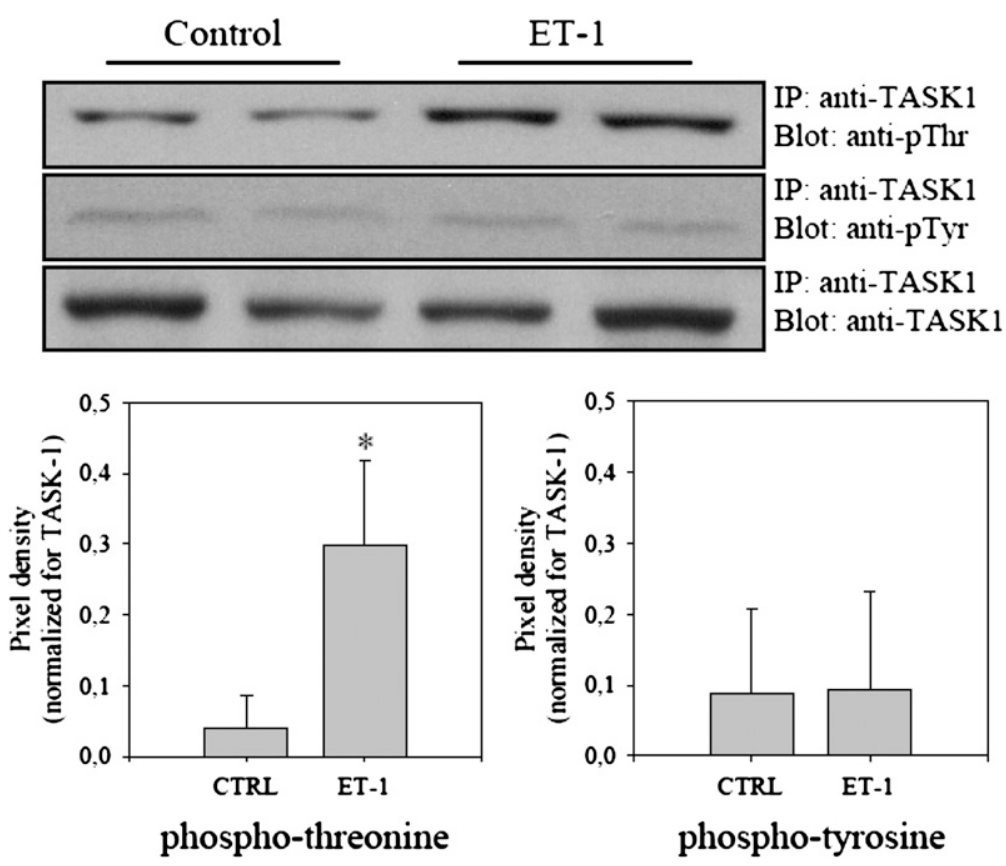

Figure 4. Protein kinase (PK)-C-dependent phosphorylation of TASK-1 by ET-1 in hPASMC. Representative results are shown of the threonine (left) and tyrosine (right) phosphorylation of TASK-1 in ET-1-treated and untreated (control) hPASMCs. Protein loading equivalence is shown by probing immunoprecipitates with an anti-TASK-1 antibody in the lower panel. hydrolysis by PLC to produce $\mathrm{IP}_{3}$ and DAG. Thus, hPASMCs were dialyzed with the $\mathrm{PIP}_{2}$ scavenger, polylysine $(30 \mu \mathrm{g} / \mathrm{ml})$, widely used to demonstrate regulation of channels by endogenous $\mathrm{PIP}_{2}$, and then superfused with ET-1 (10 nmol/L). Cells dialyzed with the internal control solution were used as a control. The application of polylysine alone significantly reduced current density to or below the level recorded after ET-1 application. When ET-1 was simultaneously applied, it did not block TASK-1 (Figure 6B). Next, to determine whether $\mathrm{IP}_{3}$ or DAG is required for the PKC activation, we incubated hPASMC with the DAG kinase inhibitor R-59949 $(30 \mu \mathrm{M})$ before ET-1 (10 nM). R-59949 inhibited TASK-1 (Figure E4). Similar data were obtained when 1-oleoyl-2-acetyl-sn-glycerol (OAG; a DAG analog; $100 \mu \mathrm{M}$ ) was applied before ET-1 in hPASMC. Application of OAG alone led to a significant inhibition of TASK-1 current, similar to the effect of ET-1 alone. Thus, the TASK-1 current was not further blocked when ET-1 was additionally applied, as shown in Figures 6C and 6D. Taken together, these results indicate that the $\mathrm{ET}_{\mathrm{A}}-\mathrm{PLC}-\mathrm{PIP}_{2}-$ DAG-PKC pathway is essential for the inhibition of TASK-1 by ET-1 in primary hPASMCs.

\section{DISCUSSION}

ET plays a central role in the pathogenesis of pulmonary hypertension, and has been extensively studied. We show here that ET inhibits the native background two-pore domain $\mathrm{K}^{+}$ channel, TASK-1, in primary hPASMCs, which sets their membrane potential as previously shown by means of TASK1-siRNA studies (14). Consequently, ET-1 depolarizes the resting membrane potential of hPASMCs at clinically relevant concentrations by dose-dependent inhibition of TASK-1. These effects are abolished by antagonists of the $\mathrm{G}$ protein-coupled receptor, $\mathrm{ET}_{\mathrm{A}}$, by $\mathrm{PIP}_{2}$ scavenger, and by inhibitors of PLC, DAG kinase, and PKC.

The effects of ET on pulmonary vessels is a matter of continued interest, because an activated ET system significantly contributes to the pathologic changes in pulmonary hypertension $(1,2)$, and ET receptor antagonists have been shown to be effective for therapy of PAH (3). Circulating ET-1 levels are elevated in animal models of PAH (23-26) and in human PAH (1, 27-29). In addition, a correlation has been demonstrated between increased ET-1 expression in the lung of patients with pulmonary hypertension and the severity of disease (2). Although this evidence indicates that the ET system plays a key role in the pathogenesis of pulmonary hypertension, the molecular targets of ET-1 have not been characterized in detail. Under normoxic conditions, the acute ET-1-induced vasoconstriction occurs via a $\mathrm{Ca}^{2+}$-dependent mechanism, mainly by $\mathrm{Ca}^{2+}$ influx through voltage-activated calcium channels, secondary to $\mathrm{K}^{+}$channel inhibition and membrane depolarization. To date, the involvement of $\mathrm{K}_{\mathrm{v}}$ (30) or ATP-dependent $\mathrm{K}$ channels $\left(\mathrm{K}_{\mathrm{ATP}}\right)$ (31) has been established. In hPASMC, we have recently described TASK- 1 channels, a member of the background two-pore domain $\mathrm{K}^{+}$channel family (14). It is noteworthy that, in these cells, no other members of the TASK
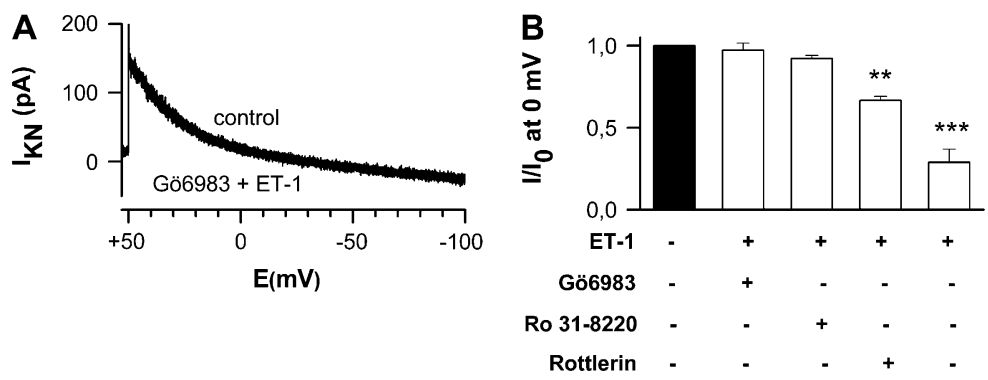

Figure 5. Effect of different PKC inhibitors on the ET-1-induced TASK-1 current inhibition in hPASMC. ( $A$ ) Representative traces show the lack of ET-1 (10 nM) effect on TASK-1 after a 1-hour preincubation with Gö6983 (10 nM). (B) Histogram summarizing the effect of ET-1 on TASK-1 current after pretreatment of hPASMCs with Ro318220 (1 $\mu \mathrm{M})$, Gö6983, or rottlerin (10 nM) ( $n=6$ for each group; ${ }^{* *} P<0.01,{ }^{* * *} p<0.001$ difference from ET-1-untreated cells). $\mathrm{I} / \mathrm{I}_{0}$ is the current in the presence of ET-1 expressed as a fraction of the current before ET-1 application. 
A
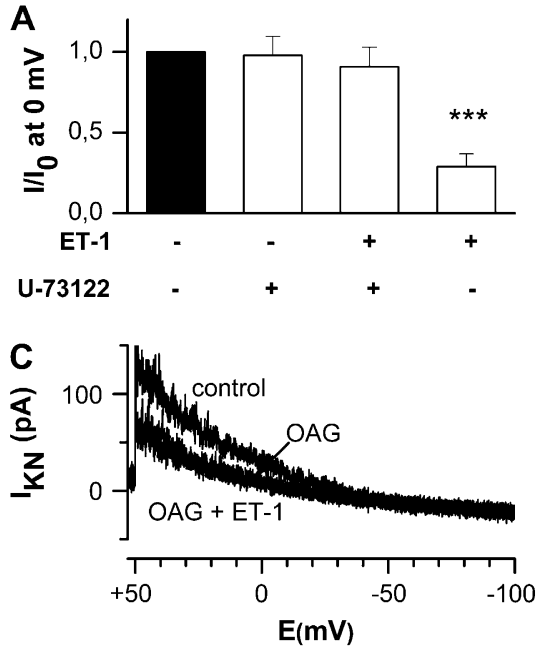
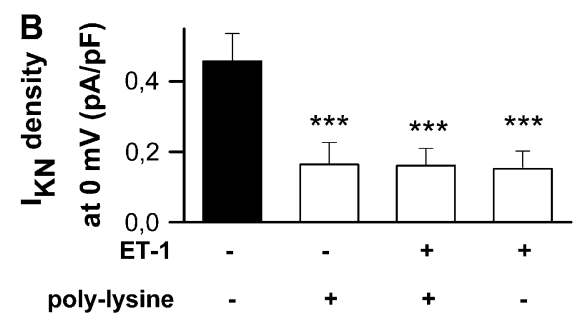

D

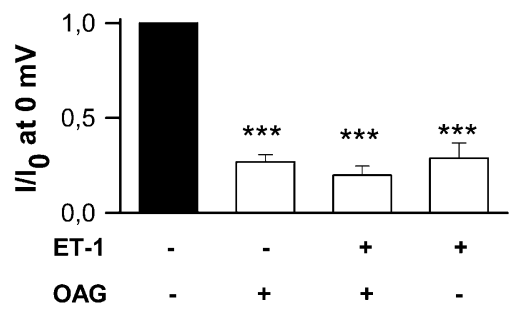

Figure 6. ET-1 signaling pathway downstream of $\mathrm{ET}_{\mathrm{A}}$ receptors to TASK-1 channels in hPASMCs. $(A)$ Mean amplitudes of currents ( \pm SEM) measured in experiments, as indicated below the graph. The amplitudes were normalized to the current amplitude obtained with the first recording without drugs (control, filled bar) ( $n=5$ for each group; ${ }^{* * *} P<0.001$ difference from control). (B) Mean amplitudes of current density ( \pm SEM) measured in experiments, as indicated below the graph. Filled bar indicates the dialysis with control pipette solution ( $n=5$ for each group; ${ }^{* * *} p<0.001$ difference from control). (C) Non-inactivating current responses of TASK-1 channels to application of the diacylglycerol (DAG) analog, OAG, and OAG plus ET-1. (D) Mean amplitudes of currents ( \pm SEM) measured in experiments, as indicated below the graph. The amplitudes were normalized to the current amplitude obtained with the recording without drugs (control, black column) ( $n=5$ each group; ${ }^{* *} p<0.001$ difference from control). channel family are expressed (14). If these channels are functionally expressed, they give rise to $\mathrm{K}^{+}$-selective current that is open at all voltages, in contrast to $\mathrm{K}_{\mathrm{v}}$ or $\mathrm{K}_{\mathrm{ATP}}$ channels, the activity of which is controlled by voltage or metabolic regulation. In fact, background $\mathrm{K}^{+}$channels, such as TASK-1, set the resting membrane potential in excitable cells $(14,32-37)$. Because TASK-1 is active at rest in hPASMC, its inhibition would lead to cell depolarization that enhances the open probability of L-type $\mathrm{Ca}^{2+}$ channels in SMCs, causing periodic $\mathrm{Ca}^{2+}$ entry, and vasoconstriction. We have now identified TASK-1 channels as an important target for ET-1 at clinically relevant concentrations, and have established a role for TASK-1 channels in the ET-1-induced membrane depolarization in primary hPASMCs using TASK-1-siRNA. This might represent an important pathway, explaining part of the vasoconstrictive and proproliferative properties of ET-1. In addition, these findings might be further supported using the isolated, perfused mouse lung model, where the effect of anandamide on ET-1induced pulmonary vasoconstriction was investigated. When anandamide was given before ET-1, the vasoconstrictive response was augmented. This suggests that anandamide and ET-1 have an additive effect on TASK-1 inhibition. However, it has to be taken into account that the endocannabinoid anandamide also acts on specific cannabinoid $\left(\mathrm{CB}_{1}\right)$ and on vanilloid receptors $\left(\mathrm{VR}_{1}\right)$. Furthermore, in the mouse model, the expression of other possible anandamide-sensitive, two-pore domain channels has not been fully characterized.

In this study, we specifically examined the signaling pathway involved in the ET-1-induced TASK-1 inhibition in primary hPASMCs. We found that antagonists of the G protein-coupled receptor, $\mathrm{ET}_{\mathrm{A}}$, fully abolished the TASK-1 inhibition in response to ET-1. The molecular basis of $\mathrm{K}^{+}$channel inhibition by an agonist that acts on Gq-coupled receptor upstream of $\mathrm{PKC}$ is reasonably well defined for some $\mathrm{K}^{+}$channels $(38,39)$, but has been controversially defined for background two-pore domain $\mathrm{K}^{+}$channels (40), and, in particular, has not yet been investigated in native vascular cells. We show that antagonists of PKC, but not antagonists of PKA, inhibited the ET-1 effect on TASK-1, suggesting that PKC mediates the agonist-induced inhibition. Our data indicate that ET-1 can stimulate the serine or threonine phosphorylation of TASK-1, and are consistent with the detection of phosphoserine in TASK-1 (41) and the presence of consensus serine and threonine PKA and PKC phosphorylation sites in the TASK-1 peptide (15). Although a tyrosine kinase



Figure 7. Schematic presentation of the ET-1 signaling pathway in hPASMCs. ET-1 binds to the $G$ proteincoupled receptor $(\mathrm{G} \alpha q) \mathrm{ET}_{\mathrm{A}}$, leading to the PKCinduced phosphorylation of TASK-1 channels through phospholipase C (PLC), phosphatidylinositol 4,5biphosphate $\left(\mathrm{PIP}_{2}\right)$, and DAG. Agonist $(+)$ and antagonist effects $(-)$ are indicated. $\mathbb{I P}_{3}$, inositol 1,4,5-triphosphate. 
consensus site is also present in the TASK-1 peptide, ET-1 did not effect tyrosine phosphorylation of TASK-1.

Several studies have examined the mechanism by which a $G$ protein-coupled receptor agonist may inhibit two-pore domain $\mathrm{K}^{+}$channels via PKC. These studies suggested that agonistinduced inhibition of the two-pore domain $\mathrm{K}^{+}$channels was due to ATP-dependent pathways (42), by depletion of $\mathrm{PIP}_{2}$ levels (43), directly by a direct action of DAG and phosphatidic acid that are generated via PLC (44), or by elevated intracellular $\mathrm{Ca}^{2+}$ levels (42). Moreover, a very recent study proposes a direct interaction of $\mathrm{G} \alpha \mathrm{q}$ with TASK-1 in a mammalian heterologous expression system (45). The results obtained from different laboratories suggest the possibility that two-pore domain channels may be modulated, not by a single mechanism, but via distinct pathways in different cell types. We found that inhibition of the PLC abolished the ET-1 effect on TASK-1 indicating that PLC is required, as also shown in Xenopus laevis oocytes (46), in contrast to the report in a mammalian heterologous expression system (35). Additional evidence comes from the use of COS-7 cells expressing TWIK-related $\mathrm{K}^{+}$(TREK)-2 and muscarinic receptor $\mathrm{M}_{3}$, where the same PLC inhibitor was applied to prevent acetylcholine-induced inhibition of TREK-2 (47). The inhibitory effect of the $\mathrm{PIP}_{2}$ scavenger on TASK-1 observed in this study confirms previously reported results obtained with different two-pore domain $\mathrm{K}^{+}$channels expressed in Xenopus oocytes (43), and strongly suggests that $\mathrm{PIP}_{2}$ hydrolysis by PLC indeed affects channel activity. Moreover, we showed that the downstream product of $\mathrm{PIP}_{2}$ hydrolysis DAG underlies the agonist-induced inhibition of TASK-1 in hPASMCs. These results are further supported by our experiments showing that the DAG kinase inhibitor abolished the ET-1 effect on TASK-1.

In conclusion, our results suggest that TASK-1 modulation by G $\alpha \mathrm{q}$ pathway is achieved by signaling rather than direct interaction between PIP $_{2}$ and TASK-1 in primary hPASMCs (43) (Figure 7). Moreover, we report here for the first time the involvement of the background two-pore domain $\mathrm{K}^{+}$channel, TASK-1, in the ET-1mediated depolarization in native hPASMC. It is tempting to hypothesize that the inhibition of the voltage-independent TASK1 channel by ET in hPASMCs contributes to the development of human pulmonary hypertension.

Conflict of Interest Statement: H.O. received lecture fees from Actelion, Encysive, and Gilead, and research grants from Actelion $(\$ 110,000)$ and Encysive $(\$ 80,000)$. A.O. received research grants from the Anniversary Fund of the Austrian National Bank $(€ 70,000)$, from the European Union $(€ 131,000$; Contract No. LSHM-CT-2005-018725, PULMOTENSION), and from the Medical University of Graz ( $€ 105,000 ;$ Ph.D. Program, Molecular Medicine).

Acknowledgments: The excellent technical assistance of Alexandra Hof, Maria Schloffer, Karin Quanz, and Elisabeth Wirnsperger is greatly appreciated.

\section{References}

1. Stewart DJ, Levy RD, Cernacek P, Langleben D. Increased plasma endothelin-1 in pulmonary hypertension: marker or mediator of disease? Ann Intern Med 1991;114:464-469.

2. Giaid A, Yanagisawa M, Langleben D, Michel RP, Levy R, Shennib H, Kimura S, Masaki T, Duguid WP, Stewart DJ. Expression of endothelin-1 in the lungs of patients with pulmonary hypertension. N Engl J Med 1993;328:1732-1739.

3. Rubin LJ, Badesch DB, Barst RJ, Galie N, Black CM, Keogh A, Pulido $\mathrm{T}$, Frost A, Roux S, Leconte I, et al. Bosentan therapy for pulmonary arterial hypertension. $N$ Engl J Med 2002;346:896-903.

4. Olschewski H, Olschewski A, Rose F, Schermuly R, Schutte H, Weissmann N, Seeger W, Grimminger F. Physiologic basis for the treatment of pulmonary hypertension. J Lab Clin Med 2001;138:287297.

5. Yanagisawa M, Kurihara H, Kimura S, Tomobe Y, Kobayashi M, Mitsui Y, Yazaki Y, Goto K, Masaki T. A novel potent vasoconstrictor peptide produced by vascular endothelial cells. Nature 1988;332:411415 .
6. Hirata Y, Takagi Y, Fukuda Y, Marumo F. Endothelin is a potent mitogen for rat vascular smooth muscle cells. Atherosclerosis 1989;78: 225-228.

7. Wort SJ, Woods M, Warner TD, Evans TW, Mitchell JA. Endogenously released endothelin-1 from human pulmonary artery smooth muscle promotes cellular proliferation: relevance to pathogenesis of pulmonary hypertension and vascular remodeling. Am J Respir Cell Mol Biol 2001;25:104-110.

8. Davie N, Haleen SJ, Upton PD, Polak JM, Yacoub MH, Morrell NW, Wharton $\mathrm{J} \mathrm{ET}_{\mathrm{A}}$ and $\mathrm{ET}_{\mathrm{B}}$ receptors modulate the proliferation of human pulmonary artery smooth muscle cells. Am J Respir Crit Care Med 2002;165:398-405.

9. Yuan XJ. Voltage-gated $\mathrm{K}^{+}$currents regulate resting membrane potential and $\left[\mathrm{Ca}^{2+}\right]_{\mathrm{i}}$ in pulmonary arterial myocytes. Circ Res 1995;77:370378.

10. Olschewski A, Hong Z, Nelson DP, Weir EK. Graded response of $\mathrm{K}^{+}$ current, membrane potential, and $\left[\mathrm{Ca}^{2+}\right]_{\mathrm{i}}$ to hypoxia in pulmonary arterial smooth muscle. Am J Physiol Lung Cell Mol Physiol 2002; 283:L1143-L1150.

11. Weir EK, Olschewski A. Role of ion channels in acute and chronic responses of the pulmonary vasculature to hypoxia. Cardiovasc Res 2006;71:630-641.

12. Yu Y, Platoshyn O, Zhang J, Krick S, Zhao Y, Rubin LJ, Rothman A, Yuan JX. c-Jun decreases voltage-gated $\mathrm{K}^{+}$channel activity in pulmonary artery smooth muscle cells. Circulation 2001;104:15571563.

13. Eddahibi S, Guignabert C, Barlier-Mur AM, Dewachter L, Fadel E, Dartevelle P, Humbert M, Simonneau G, Hanoun N, Saurini F, et al. Cross talk between endothelial and smooth muscle cells in pulmonary hypertension: critical role for serotonin-induced smooth muscle hyperplasia. Circulation 2006;113:1857-1864.

14. Olschewski A, Li Y, Tang B, Hanze J, Eul B, Bohle RM, Wilhelm J, Morty RE, Brau ME, Weir EK, et al. Impact of TASK-1 in human pulmonary artery smooth muscle cells. Circ Res 2006;98:1072-1080.

15. Duprat F, Lesage F, Fink M, Reyes R, Heurteaux C, Lazdunski M. TASK, a human background $\mathrm{K}^{+}$channel to sense external $\mathrm{pH}$ variations near physiological $\mathrm{pH}$. EMBO J 1997;16:5464-5471.

16. Buckler KJ, Williams BA, Honore E. An oxygen-, acid- and anaestheticsensitive TASK-like background potassium channel in rat arterial chemoreceptor cells. $J$ Physiol 2000;525:135-142.

17. Gurney AM, Joshi S. The role of twin pore domain and other $\mathrm{K}^{+}$ channels in hypoxic pulmonary vasoconstriction. Novartis Found Symp 2006;272:218-228.

18. Gurney AM, Osipenko ON, MacMillan D, McFarlane KM, Tate RJ, Kempsill FE. Two-pore domain $\mathrm{K}$ channel, TASK-1, in pulmonary artery smooth muscle cells. Circ Res 2003;93:957-964.

19. Vadasz I, Morty RE, Kohstall MG, Olschewski A, Grimminger F, Seeger W, Ghofrani HA. Oleic acid inhibits alveolar fluid reabsorption: a role in acute respiratory distress syndrome? Am J Respir Crit Care Med 2005;171:469-479.

20. Hsu K, Seharaseyon J, Dong P, Bour S, Marban E. Mutual functional destruction of HIV-1 Vpu and host TASK-1 channel. Mol Cell 2004; 14:259-267.

21. Weissmann N, Dietrich A, Fuchs B, Kalwa H, Ay M, Dumitrascu R, Olschewski A, Storch U, Schnitzler M, Ghofrani HA, et al. Classical transient receptor potential channel 6 (TRPC6) is essential for hypoxic pulmonary vasoconstriction and alveolar gas exchange. Proc Natl Acad Sci USA 2006;103:19093-19098.

22. Maingret F, Patel AJ, Lazdunski M, Honore E. The endocannabinoid anandamide is a direct and selective blocker of the background $\mathrm{K}^{+}$ channel TASK-1. EMBO J 2001;20:47-54.

23. Miyauchi T, Yorikane R, Sakai S, Sakurai T, Okada M, Nishikibe M, Yano M, Yamaguchi I, Sugishita Y, Goto K. Contribution of endogenous endothelin-1 to the progression of cardiopulmonary alterations in rats with monocrotaline-induced pulmonary hypertension. Circ Res 1993;73:887-897.

24. Ivy DD, Le Cras TD, Horan MP, Abman SH. Increased lung preproET1 and decreased ETB-receptor gene expression in fetal pulmonary hypertension. Am J Physiol 1998;274:L535-L541.

25. Frasch HF, Marshall C, Marshall BE. Endothelin-1 is elevated in monocrotaline pulmonary hypertension. Am J Physiol 1999;276: L304-L310.

26. Nakanishi K, Tajima F, Nakata Y, Osada H, Tachibana S, Kawai T, Torikata C, Suga T, Takishima K, Aurues T, et al. Expression of endothelin-1 in rats developing hypobaric hypoxia-induced pulmonary hypertension. Lab Invest 1999;79:1347-1357. 
27. Giaid A, Michel RP, Stewart DJ, Sheppard M, Corrin B, Hamid Q. Expression of endothelin-1 in lungs of patients with cryptogenic fibrosing alveolitis. Lancet 1993;19:1550-1554.

28. Kumar P, Kazzi NJ, Shankaran S. Plasma immunoreactive endothelin-1 concentrations in infants with persistent pulmonary hypertension of the newborn. Am J Perinatol 1996;13:335-341.

29. Yoshibayashi M, Nishioka K, Nakao K, Saito Y, Matsumura M, Ueda T, Temma S, Shirakami G, Imura H, Mikawa H. Plasma endothelin concentrations in patients with pulmonary hypertension associated with congenital heart defects:evidence for increased production of endothelin in pulmonary circulation. Circulation 1991;84:2280-2285.

30. Shimoda LA, Sylvester JT, Booth GM, Shimoda TH, Meeker S, Undem $\mathrm{BJ}$, Sham JSK. Inhibition of voltage-gated $\mathrm{K}^{+}$currents by endothelin1 in human pulmonary arterial myocytes. Am J Physiol Lung Cell Mol Physiol 2001;281:L1115-L1122.

31. Park WS, Ko EA, Han J, Kim N, Earm YE. Endothelin-1 acts via protein kinase $\mathrm{C}$ to block KATP channels in rabbit coronary and pulmonary arterial smooth muscle cells. J Cardiovasc Pharmacol 2005;45:99-108.

32. Backx PH, Marban E. Background potassium current active during the plateau of the action potential in guinea pig ventricular myocytes. Circ Res 1993;72:890-900.

33. Patel AJ, Honore E, Lesage F, Fink M, Romey G, Lazdunski M. Inhalational anesthetics activate two-pore-domain background $\mathrm{K}^{+}$ channels. Nat Neurosci 1999;2:422-426.

34. Talley EM, Sirois JE, Lei Q, Bayliss DA. Two-pore-domain (KCNK) potassium channels: dynamic roles in neuronal function. Neuroscientist 2003;9:46-56.

35. Talley EM, Bayliss DA. Modulation of TASK-1 (Kenk3) and TASK-3 (Kcnk9) potassium channels: volatile anesthetics and neurotransmitters share a molecular site of action. J Biol Chem 2002;277: 17733-17742.

36. Sirois JE, Lei Q, Talley EM, Lynch C III, Bayliss DA. The TASK-1 twopore domain $\mathrm{K}^{+}$channel is a molecular substrate for neuronal effects of inhalation anesthetics. $J$ Neurosci 2000;20:6347-6354.

37. Millar JA, Barratt L, Southan AP, Page KM, Fyffe RE, Robertson B, Mathie A. A functional role for the two-pore domain potassium channel TASK-1 in cerebellar granule neurons. Proc Natl Acad Sci USA 2000;97:3614-3618.

38. Suh BC, Horowitz LF, Hirdes W, Mackie K, Hille B. Regulation of $\mathrm{KCNQ} 2 / \mathrm{KCNQ} 3$ current by $\mathrm{G}$ protein cycling: the kinetics of receptormediated signaling by Gq. J Gen Physiol 2004;123:663-683.

39. Lei Q, Jones MB, Talley EM, Garrison JC, Bayliss DA. Molecular mechanisms mediating inhibition of $G$ protein-coupled inwardlyrectifying $\mathrm{K}^{+}$channels. Mol Cells 2003;15:1-9.

40. Mathie A. Neuronal two-pore-domain potassium channels and their regulation by G protein-coupled receptors. J Physiol 2007;578:377385 .

41. O'Kelly I, Butler MH, Zilberberg N, Goldstein SA. Forward transport: 14-3-3 binding overcomes retention in endoplasmic reticulum by dibasic signals. Cell 2002;111:577-588.

42. Enyeart JJ, Danthi SJ, Liu H, Enyeart JA. Angiotensin II inhibits bTREK-1 K ${ }^{+}$channels in adrenocortical cells by separate $\mathrm{Ca}^{2+}$ - and ATP hydrolysis-dependent mechanisms. J Biol Chem 2005;280: 30814-30828.

43. Lopes CM, Rohacs T, Czirjak G, Balla T, Enyedi P, Logothetis DE. $\mathrm{PIP}_{2}$ hydrolysis underlies agonist-induced inhibition and regulates voltage gating of two-pore domain $\mathrm{K}^{+}$channels. J Physiol 2005;564: $117-129$.

44. Chemin J, Girard C, Duprat F, Lesage F, Romey G, Lazdunski M. Mechanisms underlying excitatory effects of group I metabotropic glutamate receptors via inhibition of $2 \mathrm{P}$ domain $\mathrm{K}^{+}$channels. $E M B O$ J 2003;22:5403-5411.

45. Chen X, Talley EM, Patel N, Gomis A, McIntire WE, Dong B, Viana F, Garrison JC, Bayliss DA. Inhibition of a background potassium channel by Gq protein alpha-subunits. Proc Natl Acad Sci USA 2006;103:3422-3427.

46. Czirjak G, Petheo GL, Spat A, Enyedi P. Inhibition of TASK-1 potassium channel by phospholipase C. Am J Physiol Cell Physiol 2001;281:C700-C708.

47. Kang D, Han J, Kim D. Mechanism of inhibition of TREK-2 (K2P10.1) by the Gq-coupled M3 muscarinic receptor. Am J Physiol Cell Physiol 2006;291:C649-C656. 